\title{
Effect of Variation in Parameters of a Compliant Micro-Gripper Design
}

\author{
P. B. Darawade, M. P. Shendge, A. S. Deshmukh, S.S. Jain, R.Joshi, A. C. Mitra \\ (Department of Mechanical Engineering, M.E.S. College Of Engineering, S.P.Pune University,India)
}

\begin{abstract}
At micro-level operations, to make precise microscopic movements, there is need of aalternative mechanism other than conventional mechanism like compliant mechanism. It is rapidly increasing field where a device that uses the compliance of its structure to achieve mechanical tasks such as force and motion transmission.Due to lack of available space, the new mechanisms should be compact without compromise in their accurate \& precise performance. Unlike conventional mechanisms, compliant mechanism is monolithic, joint-free \& elastic continua.This paper chiefly focuses on the results of variation of parameters within the design of a compliant micro-gripper that uses semi-circular hinge to transmit motion. According to the requirement of an application, the various dimensions of a micro-gripper can be varied. PRBM (Pseudo Rigid Body Model) approach is used to design the micro-gripper. This paper contains analysis work using FEA software (ANSYS).
\end{abstract}

Keywords-Compliant mechanism;PRBM;monolithic;elastic continua.

\section{INTRODUCTION}

There is an increasing demand, in a very sort of fields, for the flexibility to create microscopic movements or to position things with high degree of accuracy [1]. Compliant mechanisms represent a more recent design discipline of light-weight structures. Themajorcriteriaforthedesignoflightweightstructuresarestiffness,stabilityandinsomecasesadditionallystrength. Generally, the structuresaredesignedto not deflect overadefinitevaluebelowloadusingaslessmaterialaspossible [2]. Ease of manufacture, reduced assembly expenditure, reduced friction, wear, noise, and therefore the ability to accommodate unconventional actuation schemes are a number of the various benefits of compliant mechanisms [3].In general, the stiffest structure has been considered optimal. Most structural optimization problems are developed by minimizing the compliance of a structure as an objective function. However, it is doable that higher performance is often obtained with a flexible structure rather than the stiffest structure if flexibility is with efficiency enforced within the structure. Moreover, flexible components can offer mechanical function to the structure. An example of structure with mechanical function is a compliant mechanism. Compliant mechanisms are a comparatively new breed of joint-less mechanisms that utilize elastic deformation as source of motion. They are designed to be purposely flexible, and this flexibility permits the structure to perform as a mechanism. As noted by Midha,[4]compliant mechanisms are desirable since they need fewer components, and have less wear, noise, and backlash than their rigid-body counterparts. Hence, the design of compliant mechanisms is an example of how flexible structures can give higher performance than stiff structures [4].M.R.Arvind et.al [5] developed a micro-gripper by considering the 2D- Flexure hinge parameters of circular and elliptical hinges. The finished the results of parameters and position of hinge on the stiffness and output displacement of gripper. Using PRBM approach, a micro-gripper was planned by Lin and Shih [8] and counter-link lengths were optimized. Krishnan and Saggere [6] explained micro category gripper for manipulation of complicated shaped-small sized objects for any position and projected rotational flexures idea with obtained a most geometrical advantage of 11.56. Zubir\&Shirimzadeh [7] developed a high precision parallel jaw motion micro-gripper by cantilever beam approach and using PRBM approach and attended maximum jaw displacement of 100 micron and amplification factor of 2.85 and compared results using FEM, they have additionally done optimization of rigid links. Flexural hinges design depends on capability of rotation, precision of rotation, stress levels, energy consumption and energy storage that is incredibly important. Nah \&Zhong [8] designed and invented a micro-gripper tested using piezoelectric actuator for wire and gear of varied displacement modes, with 170 microns stoke and amplification factor $3 \mathrm{~mm}$.Paros \&Weisbord firstly introduced the right circular flexure hinges [9]. They formulated simplified design equations to find compliance of flexure hinges. Many other research groups had derived compliance equations for circular hinge \& FEA results to develop empirical formula [10]. Using Casigliano's $2^{\text {nd }}$ theorem for symmetric conic structure, Lobontiu derived closed form compliance equations [11]. 


\section{METHODOLOGY AND GEOMETRICMODELLING}

The PRBM (Pseudo Rigid Body Model) is a method which is used to simplify the analysis \& design of compliant mechanisms. Though there are various methods available to design a compliant micro-gripper, PRBMapproach is used to design a micro-gripper. In PRBM method, flexible links are replaced by rigid links and rotational springs corresponding to the bending of these links. The PRBM is a bridge that connects rigidbody mechanism theory and compliant mechanism theory [12].There are various types of hinges those can be used in compliant mechanism. The main types of them are rectangular hinge, semi-circular hinge, elliptical hinge. The type of hinge selection dependsupon the application for which the mechanism is designed.In this paper, semi-circular hinge is selected.

Using a single, monolithic piece of a metal, the gripper is designed using semi-circular flexure hinges as shown in Fig.1. This monolithic design helps to overcome the disadvantages of conventional linkages \& assembly. These semi-circular hinges offer desired motion to the gripping arms. The overall motion is transferred by elastic deformation of semi-circular hinges.For micro-gripper design, dimensional constraints considered are $(70 \times 90 \mathrm{~mm})$. The distance between 2 tips of gripping arms is kept $1 \mathrm{~mm}$. Initially, other dimensions (Fig.2.) are considered as; Hinge radius (r) $=2.5 \mathrm{~mm}$, overall thickness (b) $=2 \mathrm{~mm}$, web thickness $(\mathrm{t})=1 \mathrm{~mm}$, input link $(\mathrm{h})=20 \mathrm{~mm}$.

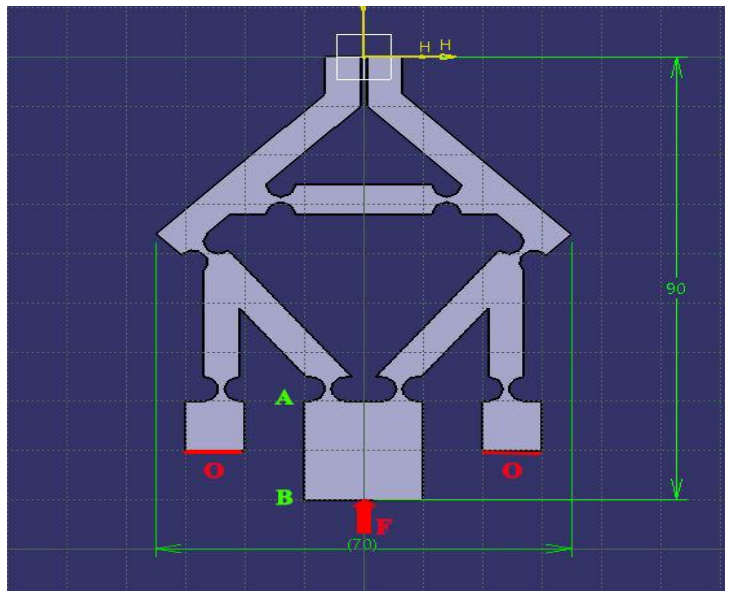

Fig.1. The modeled micro-gripper using CATIA V5

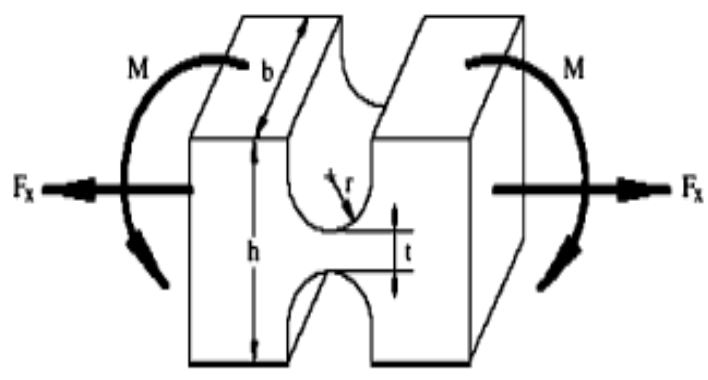

Fig.2. The generalized semi-circular hinge

\section{PRBM ANALYSIS}

The model as shown in Fig.1 isanalyzed by using equation 1 to obtain displacement at the tip of the gripping arms [13].

$$
\mathrm{X}=\frac{1}{\mathrm{~N}} \mathrm{Fh}^{2} \frac{9 \pi \mathrm{r}^{0.5}}{2 \mathrm{Ebt}^{2.5}}
$$

Input Force $(\mathrm{F})$, No. of hinges $(\mathrm{N})=8$, Elasticity $(\mathrm{E})=200 \mathrm{GPa}$, Poisson's ratio $=0.3$, Mass density $=7,850$ $\mathrm{kg} / \mathrm{m}^{3}$.

By varying different parameters like hinge radius (r), web thickness (t), overall thickness (b) and number of hinges used $(\mathrm{N}), 4$ models were designed \& compared. All the designs are analyzed by PRBM method as well as FEA (ANSYS). Both the results are compared.

\section{Finite Element ANALYSIS}

The models are saved in the format of. igs in CATIA V5. Those models are imported back into ANSYS WORKBENCH for the purpose of meshing and analysis. Simple type of meshing (Proximity\& curvature) is done. Size for meshing is chosen as fine (Fig.3.)After meshing, displacement analysis is carried out. Two ends named as $\mathrm{O}$ (Fig.1.) are fixed \& force is applied at the input link. The deformed \&undeformed shapes formed in the model are shown in the Fig.4.Fig.5. shows the minimum \& maximum von Mises stresses developed. The maximum stresses developed near the semi-circular hinge area. 

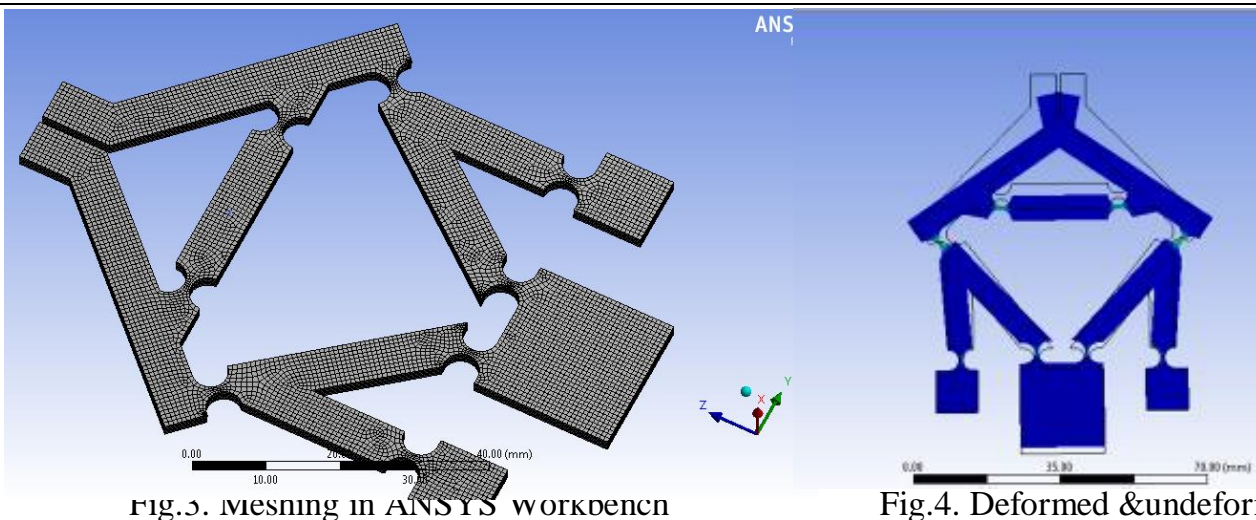

rig.J. Iviesning in Alvs r s workdencn

Fig.4. Deformed \&undeformedshape

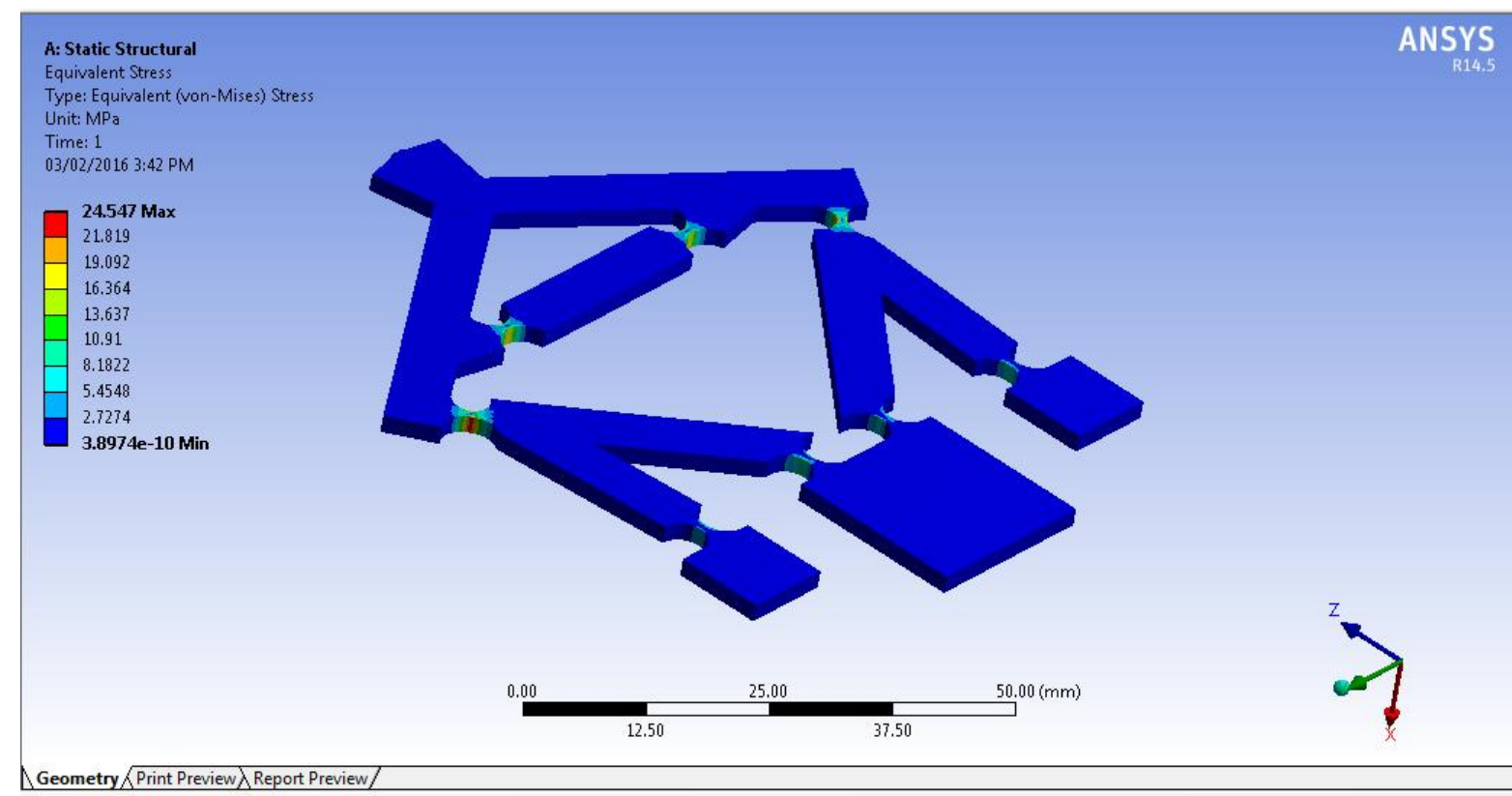

Fig.5. von Mises stresses developed

V. COMPARISON OF PRBM \& FEA RESULTS

The displacement given by PRBM at various input forces are compared with the results after FEA

Table 1 - Comparison of variation in results of Change in hinge radius

\begin{tabular}{|c|c|c|c|c|c|c|c|}
\hline $\begin{array}{c}\mathrm{F} \\
(\mathrm{N})\end{array}$ & $\begin{array}{c}\text { Hinge Radius } \\
(\mathrm{r})(\mathrm{mm})\end{array}$ & $\begin{array}{c}\text { Overall } \\
\text { Thickness } \\
(\mathrm{b})(\mathrm{mm})\end{array}$ & $\begin{array}{c}\text { Web } \\
\text { thickness } \\
(\mathrm{t})(\mathrm{mm})\end{array}$ & $\mathrm{N}$ & $\begin{array}{c}\text { Displacement } \\
\text { by PRBM } \\
(\mathrm{mm})\end{array}$ & $\begin{array}{c}\text { Displacement } \\
\text { by FEA (mm) }\end{array}$ & $\begin{array}{c}\text { Von } \\
\text { Misesstress } \\
\text { in FEA } \\
(\mathrm{MPa})\end{array}$ \\
\hline 10 & 1.5 & 2 & 1 & 8 & 0.021632056 & 0.015026 & 33.285 \\
\hline 10 & 2 & 2 & 1 & 8 & 0.024978547 & 0.020357 & 39.924 \\
\hline 10 & 2.5 & 2 & 1 & 8 & 0.027926865 & 0.026709 & 49.093 \\
\hline
\end{tabular}

Table 2 - Comparison of variation in results of Change in overall thickness

\begin{tabular}{|c|c|c|c|c|c|c|c|}
\hline $\begin{array}{c}\mathrm{F} \\
(\mathrm{N})\end{array}$ & $\begin{array}{c}\text { Hinge Radius } \\
(\mathrm{r})(\mathrm{mm})\end{array}$ & $\begin{array}{c}\text { Overall } \\
\text { Thickness } \\
(\mathrm{b})(\mathrm{mm})\end{array}$ & $\begin{array}{c}\text { Web } \\
\text { thickness } \\
(\mathrm{t})(\mathrm{mm})\end{array}$ & $\mathrm{N}$ & $\begin{array}{c}\text { Displacement } \\
\text { by PRBM } \\
(\mathrm{mm})\end{array}$ & $\begin{array}{c}\text { Displacement } \\
\text { by FEA (mm) }\end{array}$ & $\begin{array}{c}\text { Von } \\
\text { Misesstress } \\
\text { in FEA } \\
(\mathrm{MPa})\end{array}$ \\
\hline 10 & 2.5 & 2 & 1 & 8 & 0.027926865 & 0.026709 & 49.093 \\
\hline 10 & 2.5 & 3 & 1 & 8 & 0.01861791 & 0.017486 & 31.301 \\
\hline
\end{tabular}


Effect of Variation in Parameters of a Compliant Micro-Gripper Design

\begin{tabular}{|l|l|l|l|l|l|l|l|}
\hline 10 & 2.5 & 4 & 1 & 8 & 0.013963432 & 0.012919 & 23.475 \\
\hline
\end{tabular}

Table 3 - Comparison of variation in results of Change in web thickness

\begin{tabular}{|c|c|c|c|c|c|c|c|}
\hline $\mathrm{F}$ & $\begin{array}{c}\text { Hinge Radius } \\
(\mathrm{N})(\mathrm{mm})\end{array}$ & $\begin{array}{c}\text { Overall } \\
\text { Thickness } \\
(\mathrm{b})(\mathrm{mm})\end{array}$ & $\begin{array}{c}\text { Web } \\
\text { thickness } \\
(\mathrm{t})(\mathrm{mm})\end{array}$ & $\mathrm{N}$ & $\begin{array}{c}\text { Displacement } \\
\text { by PRBM } \\
(\mathrm{mm})\end{array}$ & $\begin{array}{c}\text { Displacement } \\
\text { by FEA (mm) }\end{array}$ & $\begin{array}{c}\text { Misesstress } \\
\text { in FEA } \\
(\mathrm{MPa})\end{array}$ \\
\hline 10 & 2.5 & 2 & 0.8 & 8 & 0.048786225 & 0.044635 & 71.023 \\
\hline 10 & 2.2 & 2 & 0.9 & 8 & 0.036342593 & 0.03415 & 57.533 \\
\hline 10 & 2.5 & 2 & 1 & 8 & 0.027926865 & 0.026709 & 49.093 \\
\hline
\end{tabular}

Table 4 - Comparison of variation in results of Change in number of hinges

\begin{tabular}{|c|c|c|c|c|c|c|c|}
\hline $\begin{array}{c}\mathrm{F} \\
(\mathrm{N})\end{array}$ & $\begin{array}{c}\text { Hinge Radius } \\
(\mathrm{r})(\mathrm{mm})\end{array}$ & $\begin{array}{c}\text { Overall } \\
\text { Thickness } \\
(\mathrm{b})(\mathrm{mm})\end{array}$ & $\begin{array}{c}\text { Web } \\
\text { thickness } \\
(\mathrm{t})(\mathrm{mm})\end{array}$ & $\mathrm{N}$ & $\begin{array}{c}\text { Displacement } \\
\text { by PRBM } \\
(\mathrm{mm})\end{array}$ & $\begin{array}{c}\text { Displacement } \\
\text { by FEA (mm) }\end{array}$ & $\begin{array}{c}\text { Misesstress } \\
\text { in FEA } \\
(\mathrm{MPa})\end{array}$ \\
\hline 10 & 2.5 & 2 & 1 & 6 & 0.037235819 & 0.20735 & 144.420 \\
\hline 10 & 2.5 & 2 & 1 & 8 & 0.027926865 & 0.026709 & 49.093 \\
\hline
\end{tabular}

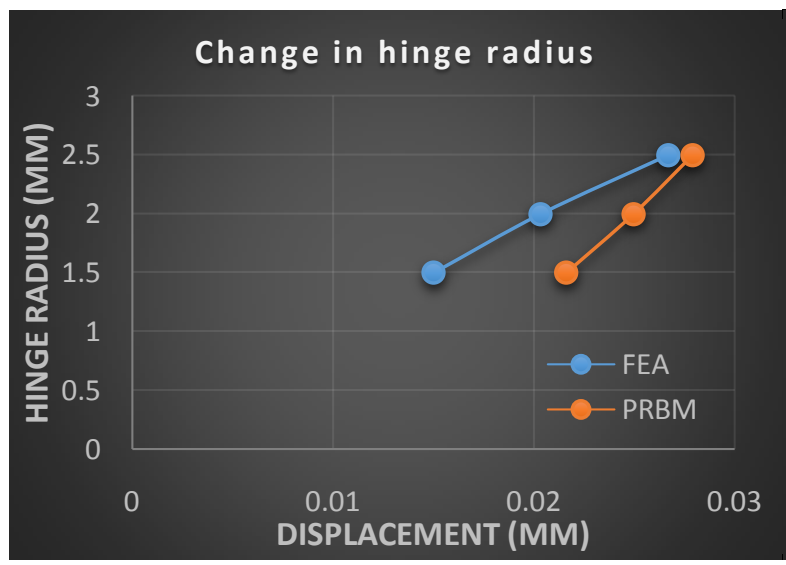

Fig.6. Change in hinges radius

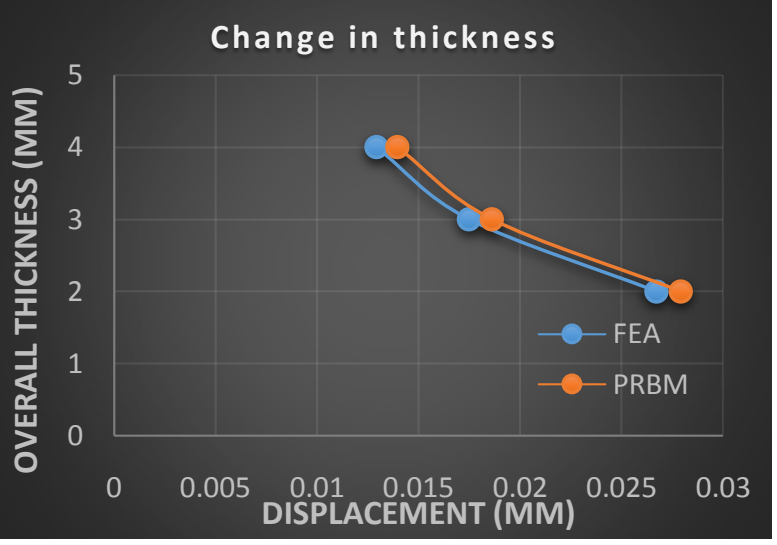

Fig.7. Change in overall thickness

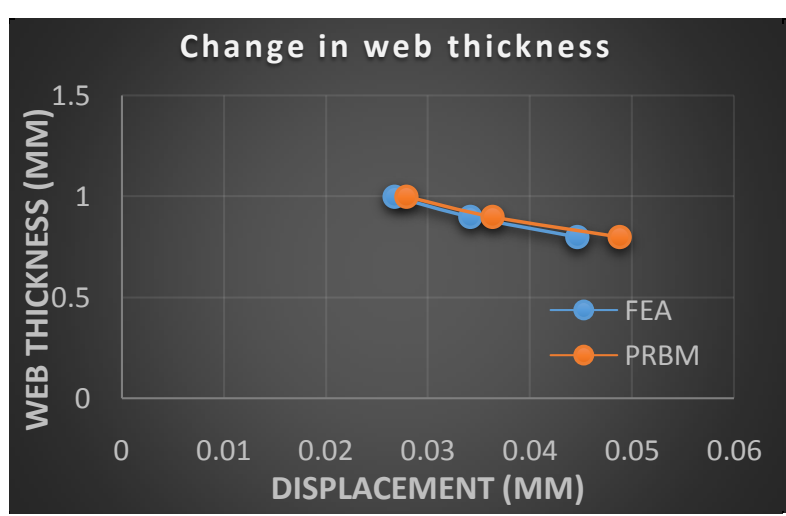

Fig.8. Change in web thickness

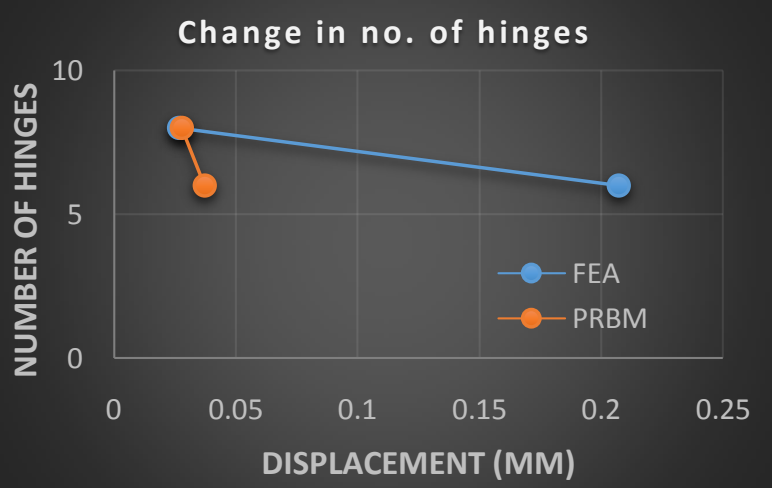

Fig.9. Change in no. of hinges

\section{CONCLUSION}

A compliant micro-gripper having semi-circular flexure hinges were designed and analyzed using PRBM method \& FEA. All different configurations were analyzed and compared with each other. Some of major observations are; 
- As radius of a semi-circular hinge (r) is increased, the deformation at the tips increases. Also the increase in (r) causes increase in stresses.

- Overall thickness (b) is inversely proportional to the displacement. But stresses reduce due to increase in material thickness.

- If web thickness ( $t$ ) is reduced, more deflection is obtained at the cost of increase in stresses.

- Number of hinges plays vital role in design of compliant mechanism. It decides the distribution of force and stresses throughout the mechanism. If numbers of hinges are increased, the deformation reduces and stresses also get reduced.

\section{REFERENCES}

[1] Dan Zhang, Kayla Viegas, Zhen Gao, YunjianGe 'Modeling and Analysis of an Enhanced Compliant Parallel Mechanism for High Accuracy Micro Motion', Proceedings of the $7^{\text {th }}$ World Congress on Intelligent Control and AutomationJune 25 - 27, 2008, Chongqing, China, Pages 2289-2294.

[2] Michael Sauter 'A Graph-based Optimization Method for the Design of Compliant Mechanisms and Structures'A dissertation submitted to the Swiss Federal Institute of Technology Zurich 2008, DISS. ETH NO. 17787

[3] G.K. Ananthasuresh, 'A New Design Paradigm for Micro-electro-mechanical Systems \& Investigations on the Compliant Mechanism Synthesis 'University of Michigan, Ann Arbor,MI, 1994.

[4] A. Midha, T. W. Norton and L. L. Howell, 'The nomenclature and classification of compliant mechanisms: the components of mechanisms' Proc. ASME Design Engineering Technical Conf., Arizona, 1992, Vol. 47, Pages 13-16.

[5] M. R. Aravind Raghavendra, A. Senthil Kumar, Bhat Nikhil Jagdish, 'Design and analysis of flexurehinge parameters in Micro-gripper', The International Journal of Advanced Manufacturing Technology, Aug.2010, Volume-49, Pages 1185-1193.

[6] SandeepKrishnan, LaxmanSaggere (Dept. of Mech.\& Industrial Engg., University of Illinois at Chicago, Chicago, IL 60607, US.A), 'Design and development of a novel micro-clasp gripper for micromanipulation of complex-shaped objects', Sensors and Actuators A: Physical, Apr.2012, Volume 176, Pages 110-123.

[7] MohdNashrulMohdZubir, BijanShirinzadeh, 'Development of a high precision flexure-based microgripper', Precision Engineering, 2008, Volume-33, Pages 362-370.

[8] S.K. Nah, Z.W. Zhong(School of Mechanical and Aerospace Engineering, Nanyang Technological University, 50 Nanyang Avenue, Singapore 639798, Republic of Singapore), 'A microgripper using piezoelectric actuation for micro-object manipulation', Sensors and Actuators A: Physical, 2006, Volume-133, Pages 218-224.

[9] Paros LM, Weisbord L (1965) 'How to design flexure hinges', Mach Des 37:151-156

[10] S. Smith, D G Chetwynd, D K Bowen, 'Design and assessment of monolithic high precision translation mechanisms', JOURNAL OF PHYSICS SCIENTIFIC INSTRUMENTS, 1987, 20(8):977983.

[11] N. Lobontiu, Jeffrey S.N. Paine, E. Garcia, M. Goldfarb, 'Design of symmetric conic section flexure hinges based on closed-form compliance equations', Mechanism and Machine Theory, May 2002, Volume 37, Pages 477-498.

[12] Larry L. Howell, 'Compliant Mechanisms', A Wiley-Interscience Publication, John Wiley \& Sons, 2001 .

[13] B.Deshmukh, S. Pardeshi, R. Mistry, S.Kandharkar, S.Wagh, 'Development of a Four bar Compliant Mechanism using Pseudo Rigid Body Model (PRBM)', Procedia Materials Science, 2014, Volume 6, Pages 1034 - 1039. 